Popularizar la ciencia: consideraciones sobre la "otredad" y sus implicaciones éticas

Página inicial:53 - Página final:67

TIPO DE ARTíCULO: de Investigación

\title{
Popularizar la ciencia: consideraciones sobre la "otredad" y sus implicaciones éticas
}

\author{
Popularizing Science: Some Considerations
}

About the "otherness" and its Ethical Implications.

\section{Resumen:}

¿Por qué popularizar la ciencia? Existen hoy día diferentes propuestas para comunicar la ciencia, aunque el mayor énfasis está dirigido en la divulgación. En esta reflexión, que ha partido de análisis previos, se establecen las diferencias entre: a) el sentido llano de comunicar o divulgar la ciencia, y b) popularizarla. Todo proceso de comunicación de la ciencia, en el sentido de su popularización, debe considerar los contenidos científicos como objetos de la comunicación, productos de un proceso social que obedecen a un contexto histórico, económico, político y cultural en el cual han sido producidos y desde el cual es posible comprenderlos. El escrito ofrece algunas aportaciones para popularizar la ciencia, con sustentos teóricos retomados de los principios de Freire, Kaplún y Moscovici

\section{Palabras Claves:}

ciencia, divulgación, popularización, otredad

\section{Abstract:}

Why popularize science? Nowadays, there are different proposals to communicate science, although its major interest lies in spreading it. Based on this reflection, which has started from a previous analysis, are established the differences between: a) the simple sense of communicating or spreading science and b) popularizing it. Every communication process of science, in the sense of popularizing it, must take into account the scientific contents as objects of communication, which are products of a social process and respond to a historic, economic, political and cultural context in which they have been produced and from which it is possible to understand them. This paper provides some contributions to popularize science, with a theoretical background based on the principles by Freire, Kaplun and Moscovici.

\section{Key words:}

Science, spreading, popularization, otherness.

`Doctorando en Educación, CUCSH, MÉXICO. silvidom@cencar.udg.mxsilvia_dominguez_g@hotmail.com 


\section{Introducción}

No hay titubeo al decir que uno de los grandes logros y retos del hombre ha sido la construcción de la ciencia. Ésta, sin embargo, suele estar restringida a un grupo de actores que considera que les pertenece, y que sólo circula en más de las ocasiones entre ellos mismos (Bourdieu, 2000). Y cuando se trata de compartir los conocimientos, productos de la investigación y de sus procesos complejos imbricados, éstos se externan en muchas ocasiones de una manera confusa, difícil, poco comunicable, no solamente por los propios investigadores, sino a través de aquellos que difunden estos conocimientos, los cuales dejan ver sus propias percepciones acerca de la ciencia, no siempre deseables.

La importancia de ciertos valores fundamentales como el respeto, la responsabilidad, la libertad, la igualdad, la solidaridad, la actitud del diálogo, entre otros, deben ser contemplados y ponderados tanto por los investigadores, en su quehacer cotidiano de la ciencia-cualquiera que sea su adscripción paradigmática-, así como los que participan estos conocimientos, productos de rigurosas investigaciones, al resto de la población.

El cómo reaccione y participe el "otro" en la comunicación y aprehensión de la ciencia, dependerá, entre muchos otros factores, de cómo se comparta, se entienda y se represente socialmente ésta.

Los párrafos siguientes, son productos de una reflexión que considera al propio investigador y al "otro" como personas implicadas en el proceso de producción de conocimientos, con consideraciones éticas tanto implícitas como explícitas; se precisan tres apartados: 1. Diversos acercamientos a la divulgación de la ciencia 2. Cómo se ha concebido al "otro" bajo algunas perspectivas de divulgación, y 3 . Una propuesta sobre la popularización de la ciencia.

\section{Diversos acercamientos en la divulgación de la ciencia²}

Para entender el sentido de la divulgación de la ciencia, proceso en que el "otro" está siempre presente, primeramente, hay que diferenciar dos significados en torno a la comunicación: transitivo uno, reflexivo el otro.

El significado transitivo de comunicar es equiparable a informar, transmitir, persuadir o interpelar al otro, por lo que la comunicación está íntimamente relacionada con el término de "divulgación", ya que comunicar es transmitir a las personas algo que un actor o un sector social especializado posee y ha construido. En este sentido, el primer término está emparentado con el poder, puesto que uno es el que experimenta el proceso de conocimiento -el científico, por 
ejemplo- y el "otro" sólo es referido o ignorado en este proceso. Paulo Freire (1969, 1973) denominó a este tipo de relación como "alienación de la ignorancia" significando con ello que el "otro" es considerado como el que no sabe y que, además, no puede hacer un proceso de conocimiento "completo" por sí solo, sino a través de la ayuda del experto.

El segundo significado de comunicación es el reflexivo, el cual implica que la comunicación, antes que comunicar es comunicarse, compartir y dialogar. El significado reflexivo ha sido relacionado bajo algunas perspectivas con "comunión", un sentido religioso que con el tiempo ha terminado articulándose con la idea de Habermas (1992), acerca de una posible "comunidad ideal de comunicación", que implica una comunidad de lenguaje donde la esperanza está puesta en la voluntad subjetiva de los participantes, lo que contribuye a consagrar a la comunicación intersubjetiva.

No obstante, comunicarse no es sólo una situación armoniosa que hace posible el compartir y el establecer acuerdos ya que rara vez la comunicación es simétrica (entre iguales) y armoniosa (no conflictiva). Por lo tanto, de acuerdo a Huergo (2001) se va a considerar a la comunicación dialógica como un encuentro, antes que como un acuerdo, donde los que se encuentran cargan con sus memorias, sus conflictos, sus diferencias. Comunicarse, entonces, no es sólo entablar relaciones dialógicas interpersonales, cara a cara, sino que implica la participación en una comunidad determinada por situaciones políticas, geográficas e históricas.

La comunicación es un proceso histórico, social y cultural en el cual se producen significados y se construyen sentidos. Sánchez-Ruiz (2004:15) señala: "Cuando de comunicación humana hablamos, nos referimos al proceso de producción de sentido mediante el intercambio de señales y mensajes entre sujetos humanos". Esto quiere decir que en los procesos de comunicación se otorgan significados a determinados hechos, relaciones, situaciones, productos, etc.

Comprender cómo la comunicación o qué noción de comunicación está operando en esas nociones de divulgación, va a permitir arribar al sentido de abandonar la noción de divulgación y reemplazarla por la de "popularización", más no como un simple cambio de término, sino como un cambio de perspectiva y de posicionamiento frente al problema de la relación más amplia entre ciencia y sociedad. Hechas estas diferencias, pasemos a señalar varios enfoques que bajo el término de divulgación han perfilado algunas acciones en la propagación de la ciencia.

1.1.La primera perspectiva o enfoque está representada por la tradición iluminista. En esta tradición, íntimamente vinculada al proyecto de la modernidad (Habermas, 1988), la 
racionalidad necesitó distinguirse en tres esferas autónomas: la ciencia, el arte y la moral, organizadas en torno a aspectos específicos de su validez. Pero, por otro lado, y para que la racionalidad en ascenso pudiera legitimarse, debió realizarse una profunda distinción entre la cultura de los expertos y la cultura del público. Articulada con el desarrollo del capitalismo, esta perspectiva deseaba emplear esa acumulación de cultura especializada en la organización racional de la vida social cotidiana, para promover el control y dominio de las fuerzas naturales, un modo de comprensión del mundo y del individuo y la felicidad de todos los hombres. De allí que se consagró la idea de que, para vivir en la sociedad es necesario un modo de comunicación determinado: racional, transparente, ordenado, controlado.

1.2. La segunda perspectiva está relacionada con la tradición escolarizada, en la que existe una institución destinada a transmitir los productos de la ciencia "moderna" y a llevar moralización, orden y control. Existen tres críticas a esta tradición:

1.2.1. Para su cometido, las instituciones, en el caso latinoamericano, fueron en general reproductoras, privilegiaron ideales extranjeros que, a su vez, cargaban conflictos y pugnas pertenecientes a otros contextos, que en muchos casos nada tenían que ver con la propia historia.

1.2.2. Los contenidos debían tener relación con la ciencia y además estos contenidos, supuestamente científicos, que se transmitían en la escuela coincidían a su vez con las producciones del conocimiento científico hegemónicas. Se reconoce en este tipo de acciones una transposición, hasta cierto punto arbitraria, de las producciones científicas, cuyos filtros suelen ser los programas, los manuales y la propia construcción que de ellos hace el docente.

1.2.3. La escuela se concentró en un tipo de cultura (privilegiada por varios de los países desarrollados) y despreció otras: se centró en el orden y claridad de la escritura, descuidando las culturas orales, así como en el disciplinamiento de conductas y la homogenización de gustos, costumbres y normas, frente a las diferencias culturales (Foucault, 1976); además, se centró en un ideal de ciudadano idóneo compatible con el ideal burgués capitalista en perjuicio del sujeto político autónomo. En esta tradición se observa una forma de comunicación como "educación bancaria" (Freire, 1973), donde un grupo posee la verdad, el saber y las normas y las deposita en el otro, de acuerdo a un modelo predeterminado.

1.3.El tercer enfoque está representada por el difusionismo desarrollista. Bajo esta perspectiva, de lo que se trata es de difundir la racionalidad y la cultura modernizadoras de las naciones y los sectores nacionales desarrollados, a los países no desarrollados, con culturas muy tradicionales. La difusión de innovaciones, desde el punto de vista comunicacional, consiste en transmitir los 
logros de la modernización y la vez persuadir a los receptores o usuarios de los beneficios de la misma. Esto implica la hegemonización de la concepción de desarrollo, ya que éste significa una modernización automática por la vía de la adopción y uso de innovaciones, en especial tecnológicas, pero con ausencias de contextualización, es decir, no se consideran el tipo de culturas a las que van dirigidas.

1.4. La cuarta perspectiva es la de la tecnoutopía emergente. Esta corresponde a una unión del difusionismo desarrollista (frutos de la modernización), y a la vez incorpora los logros de la revolución científico-tecnológica bajo el lema "una vida feliz y cómoda para todos". Como utopía tecnológica, tiene una fuerte carga mística en cuanto pone en el centro de su dinámica la creencia y la ilusión de un mundo mejor sobre la base de la incorporación de los avances tecnológicos. Pero, también refuerza la desarticulación entre tecnología, sociedad y poder, puesto que presenta los procesos como despojados de todo conflicto. Se supone que el instrumento ha sido diseñado para que la vida del hombre sea menos penosa, pero los instrumentos han sido inventados por el hombre para erigir un mundo, una totalidad de sentidos que reclama de la incesante invención de instrumentos que superen a los anteriores y que tiene como raíz una permanente insatisfacción (Arendt, 1993). En cuanto a la perspectiva comunicacional, la tecnoutopía emergente cree que la mera incorporación de aparatos, sistemas, redes y entornos tecnológicos tiene como efecto una vida más armoniosa y más democrática centrada casi siempre en los méritos individuales y una calificación de las diferentes prácticas cotidianas.

1.5. La última perspectiva ha tenido especial repercusión en políticas, acciones y prácticas sociales contemporáneas ya que pone énfasis en la elaboración de "estrategias" para la divulgación científica. Existen algunas acepciones sobre el término de "estrategia": una cercana a maniobras bélicas, en este caso, contra las prácticas culturales relacionadas con la ignorancia, la confusión, la incompetencia o la ineficacia, y otro significado es la que está emparentado con proyectos transformadores relacionados con las propuestas freireanas, que es por la cual apostamos.

\section{Cómo se ha concebido al "otro" bajo estas perspectivas de divulgación}

Tomando como sostén las perspectivas anteriores, Huergo (2001) señala que provienen de diferentes visiones o construcciones del "otro":

2.1. El "otro" es sujeto de fuerzas naturales sobre las cuales es preciso echar luz a través de procesos de concientización o de control y dominio, a fin de sortear diferentes frentes de confrontación contra la ciencia. 
2.2. El "otro" es sujeto de diferentes grados de ignorancia, y su moralidad es un fuerte obstáculo para la divulgación de la ciencia.

2.3. El "otro" posee una cultura tradicional sobre la cual, a través de la persuasión y la planificación racional, han de difundirse los avances de la ciencia y la tecnología.

2.4. El "otro" sufre diferentes grados de incompetencia e inadecuación, frente a los que la divulgación, en especial, debe trabajar en el sentido de producir entornos y redes correspondientes con los avances tecnológicos.

2.5. El "otro" es, en diferentes formas, el enemigo, a quien se debe "desarmar" desarticulando sus fuerzas, su territorio y su voluntad; es una exterioridad sobre la cual trabaja la divulgación.

2.6. El "otro" es el cliente, el consumidor o el usuario de los productos de la ciencia y la tecnología; para él están destinadas todas las estrategias de divulgación para el consumismo.

En general, estas maneras de entender la comunicación como una mera divulgación y el significado que se le da al "otro", resultan un fuerte obstáculo al imaginar las políticas, los programas, los proyectos y las acciones. Como Freire (1974) decía, el término extensión se encuentra en relación significativa con transmisión, entrega, donación, mesianismo, mecanicismo, invasión cultural, manipulación, es decir, con el significado transitivo de comunicación. De modo que extensión puede entenderse como la acción de persuadir a las culturas populares a aceptar la propaganda (en el sentido de la propagación del contenido que se divulga) y aplicar las innovaciones, en este caso, de la ciencia y la tecnología; esta es la tarea del divulgacionista o extensionista; es decir, puede entenderse como una macro estrategia del difusionismo.

Como dice Arendt (1996), quien quiera educar a los adultos, en realidad quiere obrar como su guardián y apartarlos de la actividad política (y de la ciencia, en el sentido de que haciendo ciencia también se hace política); como no se puede, o más bien, no se quiere educar a los adultos, la palabra "educación" (como por ejemplo, el educar en la ciencia) tiene un sonido perverso en política, ya que se habla de educación, pero la meta indudable es la coacción (consciente en algunos casos, pero otros de manera inconsciente) sin el uso de la fuerza.

Por otra parte, los prejuicios y estereotipos sobre el otro (ya sea como sujeto de fuerzas naturales, de la ignorancia, de la tradición, como el incompetente, el enemigo o simplemente el usuario o consumidor) obstaculizan no sólo la posibilidad de considerar que la ciencia es una construcción social que atañe a todos los grupos (macro, meso y micro) y que se establece en relación con diferentes culturas, sino también la comprensión del otro, no ya como masa 
indiferenciada de no-especialistas o de simples observadores pasivos, sino más bien como sujeto social, como sujeto con conocimiento. Esto implica considerar al otro como sujeto de comunicación, y no como objeto o destinatario; un sujeto que debe ser involucrado en un proceso colectivo de conocimiento, razonamiento, pensamiento y crítica acerca de cuestiones científicas y tecnológicas. Lo que implica, por otro lado, trabajar con el otro, y no para el otro, produciendo una ruptura en las relaciones basadas en la autoridad cognitiva, en la dominación del especialista o en la manipulación científica.

Abriendo el abanico de perspectivas y de posibles miradas, lo anterior nos lleva a considerar, como bien menciona Sánchez de Aparicio y Benítez (2007) que la persona del investigador para reconocerse a sí mismo, existe sólo gracias al tú, esto es al otro, la otredad. Apunta el autor:

"Sin los demás yo estoy vacío, no soy nadie. El hombre adquiere sentido, significado en la relación; no sólo es un ser en relación es un ser de relaciones, que requieren estudiarse para comprenderlo. Venimos al mundo en una sociedad que siempre ha sido, quizá sin tomar conciencia de ello: geocultural, geohistórica, geopolítica, condición triple que incide profundamente en la interrelación humana. Si en tiempos pasados fue más sencilla, en un marco de mayor estabilidad y menor cambio, hoy se ha vuelto un paquete abundante, complejo y complicado, con un cambio continuo, vertiginoso y conflictivo; ¿́pero qué le hacemos? Hay que aceptarlo y convertirlo en fuente de oportunidades" (págs. 3-4)

En definitiva, romper no sólo con los prejuicios y estereotipos sobre el otro, sino con los prejuicios y estereotipos sobre el conocimiento científico y sobre la comunicación significa abandonar la perspectiva de la divulgación y trabajar en el sentido de lo que se ha dado en llamar "popularización de la ciencia".

\section{La popularización de la ciencia}

Estamos de acuerdo con Moscovici (1979) y De Certeau (1996) acerca de sus afirmaciones sobre la necesidad de analizar el "hacer cotidiano" relacionadas con diferentes trayectorias, con diversas maneras de utilización y consumo de productos culturales, así como en la observación del sentido común. En cuanto proceso de comunicación, la "popularización" no sólo consiste en un persistente involucramiento de los sujetos en los procesos colectivos de conocimiento, razonamiento, pensamiento y crítica acerca de cuestiones y hechos, sino que además consiste en una persistente democratización de las producciones científicotecnológicas, que consiste en trabajar en favor del acceso, la apropiación y el uso de las producciones alcanzadas por una sociedad, que dejan de ser individuales o particulares, para 
convertirse en colectivas. La comunicación dialógica no sólo gira en torno a formas, a ocasionales encuentros espontáneos, sino que se refiere a contenidos, a producciones sociales, sobre las cuales se basan los procesos de apropiación y de producción de significados.

Todo proceso de comunicación de la ciencia, en el sentido de su popularización, debe considerar los contenidos científicos como objetos de la comunicación, productos de un proceso social que obedecen a un contexto histórico, económico, político y cultural en el cual han sido producidos y desde el cual es posible comprenderlos. En ese sentido, bajo el estudio de la teoría de las representaciones sociales (Moscovici, 1979), combinadas con las propuestas de Freire (1973) y Kaplún (1992) es posible establecer procesos de comunicación de la ciencia que se hacen patentes a través de las consideraciones de estos tres autores, propuestas que están muy relacionados entre sí.

Iniciamos con una propuesta que retoma los principios básicos de Paulo Freire, los cuales son ampliamente reconocidos en diferentes ámbitos educativos, particularmente con los adultos, para pasar a las siguientes dos que continúan con elementos propuestos por M. Kaplún y Serge Moscovici.

3.1. El proceso de reconocimiento de lo que Freire (1973) ha denominado el "universo vocabular" del interlocutor, del otro. Paulo Freire expresa que el estudio del universo vocabular recoge los vocablos típicos del pueblo, es decir, sus expresiones particulares, vocablos ligados a la experiencia de los grupos, de los que el educador (o el comunicador, o el popularizador de la ciencia) forma parte; las palabras generadoras deberían salir de este estudio y no de una selección hecha por el comunicador en su escritorio, por más técnicamente bien escogidas que estuviesen.

En este sentido, las "palabras generadoras" pueden entenderse, en sentido amplio, como aquellos núcleos problemáticos que dan origen a todo proceso de comunicación; la clave es percibir y partir desde el "aquí y ahora" de los sectores populares, con el objeto que estos sectores puedan vivir adecuadamente un proceso de apropiación y producción de significados que los dignifique efectivamente, y no procesos que sólo tranquilicen las conciencias de quienes elaboran las estrategias.

La idea, entonces, es partir de la realidad de la que se depende y de la conciencia que de ella se tenga, de manera de que lo que se comunica adquiera sentido en ese contexto, y no que quede como algo superpuesto y aislado. Esa búsqueda de los problemas que se experimentan en la realidad y de la Interpretación que los sujetos hacen de ellos, no sólo avala una "motivación" por parte de los interlocutores, sino que esa búsqueda es lo que instaura el diálogo en los procesos de comunicación. 
Conocer al otro, al interlocutor, a su universo vocabular, es también conocer su campo de significación, desde el cual el otro se comunica. Esto es clave en cuanto al desarrollo de procesos de conocimiento, como el científico, por ejemplo, porque un campo de significación es un conjunto de valores, lenguajes, códigos e ideologías, compartidos por una cultura o una subcultura, desde los que los sujetos pueden conocer la realidad. Los campos de significación iluminan y a la vez oscurecen el conocimiento. Lo iluminan, en tanto a partir de ellos se integran nuevos aspectos de la realidad; lo oscurecen, cada vez que se enfrentan con problemas para los cuales los campos de significación no están preparados para conocer.

Frente a ellos, el conocimiento humano puede replegarse, negándose a conocer, o bien, puede vivenciar una "ruptura epistemológica" del campo de significación. En este último caso, el conocimiento de un problema radicalmente novedoso se produce gracias a que el campo de significación se amplía, se reconfigura, se modifica, provocado por la realidad y con el fin de hacer posible ese nuevo conocimiento.

3.2. El proceso de "prealimentación" que conforme a Kaplún (1992, 1996) consiste en una puesta en práctica del reconocimiento del universo vocabular. Kaplún sostiene que un enfoque comunicacional supone incluir, para la producción de todo material, una intensa etapa de prealimentación, encaminada a captar las ideas, percepciones, experiencias y expectativas de los potenciales interlocutores, descubriendo otras prácticas que es necesario incorporar y valorar, así como otras percepciones y otras preguntas -e incluso otros vacíos- a las que es preciso atender. De lo anterior se obtienen materiales en los que el interlocutor se reconoce y se siente presente, productos comunicativos, que conversan con el interlocutor y con los que él, a su vez, puede entrar en diálogo.

La prealimentación permite cambiar el modo de comunicación, al poner al destinatario al principio del esquema emisor-mensaje-receptor, y no sólo al final, originando e inspirando mensajes ya que su propósito es recoger las experiencias, necesidades y aspiraciones de la comunidad. Dos cuestiones claves señala Kaplún (1992): la primera, que no se trata sólo de reflejar o reproducir mecánicamente a la comunidad, sus percepciones y sus visiones de la realidad; la segunda, que el autorreconocimiento de la comunidad en los mensajes, le permita problematizar y analizar críticamente los problemas cotidianos.

Por tales razones la prealimentación es central ya que permite comprender el pensamiento del interlocutor, acceder a su universo simbólico, descubrir sus códigos -no sólo lingüísticos sino también experienciales, ideológicos, culturales-, sus vivencias cotidianas, sus preocupaciones; sus preguntas y sus expectativas; sus conocimientos y sus desconocimientos; es decir, conocer sus representaciones sociales de la ciencia. 
Se hace necesario destacar tres reconocimientos que hace Kaplún (ibid), que distancian los propósitos de la prealimentación de un mero reflejo o reproducción de lo popular: en primer lugar, el reconocimiento de la ampliación de lo simbólico y los códigos a cuestiones culturales, y no sólo lingüísticas, lo que hace del mensaje algo más complejo que la pura devolución de terminologías usadas por la comunidad; en segundo lugar, el reconocimiento de las contradicciones existentes al interior de la vida cultural cotidiana de los sectores folklóricos o románticos; y en tercer lugar, el reconocimiento de la necesidad de partir de la percepción y la visión popular (el "sentido común" de acuerdo a Moscovici [1979], que sin el acercamiento a éste, es como desaparecerlo y según señala Arendt [1996], la desaparición del sentido común es el signo más claro de la crisis en la educación) provocando identificaciones e involucramientos, pero para provocar desde allí una comprensión intelectual, en el sentido de elevación del nivel de conciencia.

3.3. Las ideas anteriores caben muy bien con la propuesta teórica acerca de las representaciones sociales cuyo fundador es Moscovici (1979). Más żpor qué adentrarse en este campo tomando como sustento teórico-epistémico a las representaciones sociales? Robert Farr (1993) a finales del siglo pasado ya había señalado con bastante certeza que la teoría de las representaciones sociales encaja perfectamente para abordar investigaciones empíricas sobre la percepción pública de la ciencia porque, además de que los científicos sociales están interesados en estudiar qué hay detrás de las percepciones relacionadas con cualquier ámbito de la ciencia en las personas, éstas últimas están interesadas en entender a la ciencia a "su manera" (esto es, a través del "sentido común"). De hecho, el estudio inicial de Serge Moscovici ${ }^{3}$ es una investigación que, de acuerdo con Farr (1993), en aquel entonces hubiera quedado inserta en el ámbito de la "percepción pública de la ciencia" de haber existido tal movimiento. ${ }^{4}$

Por otro lado, estudiar lo que representa la ciencia para los otros, es decir, la otredad a través de la teoría de las representaciones sociales, permite adentrarnos en su construcción social y de los significados conferidos a ésta por varias razones, además de las ya explicitadas anteriormente: ${ }^{5}$

- Las representaciones sociales designan el saber del sentido común, el pensamiento natural; es un conocimiento práctico, socialmente elaborado y compartido (Moscovici, 1979; Farr y Moscovici, 1984).

- Las representaciones sociales son parte del pensamiento social simbólico, de la conciencia social y de cualquier forma de vida social y mental que presuponga lenguaje. Son un tipo de organización simbólica del conocimiento y el lenguaje, que se ajusta al estudio del sentido común, el conocimiento corriente (Moscovici y Marková, 2003). 
- Son sistemas de interpretación de la realidad (Jodelet, 1989), construida socialmente.

- Uno de los postulados fundamentales en el estudio de las representaciones sociales es el de una interrelación, una correspondencia entre las formas de organización en las comunicaciones sociales y las modalidades del pensamiento social, visto desde el punto de vista de sus categorías, de sus operaciones y de su lógica (Jodelet, 1989).

- Se definen por su contenido, que está integrado por un conjunto de informaciones, imágenes, opiniones (universos de opiniones), actitudes, creencias y estereotipos con respecto a un objeto, dentro de un contexto social (Moscovici, 1979).

- Pueden ser estudiadas mediante la articulación de elementos afectivos, mentales y sociales, donde la integración del lenguaje y la comunicación se consideran vitales en las relaciones sociales que afectan a las representaciones y la realidad material social e ideal sobre las que intervienen (Moscovici, 1979; Jodelet, 1989).

- La representación social es un proceso de construcción de lo real, actúa simultáneamente sobre el estímulo y sobre la respuesta (Herzlich, 1975).

- Como teoría, la representación social involucra una serie de relaciones conceptuales para dar cuenta de cómo los individuos reconstruyen los hechos sociales (la ciencia, por ejemplo) a través del sentido común y de cómo éstos son interpretados, sobre todo para mantenerse en comunicación y tener una visión del mundo. Como expresión del pensamiento social, son las formas de conocimiento de sentido común, diferentes a las formas de conocimiento sistemático e institucionalizado que son las propias ciencias (Moscovici, 1988).

- Las representaciones son sociales y nos orientan en la manera de designar y definir conjuntamente los diferentes aspectos de nuestra realidad diaria, en la manera de interpretarlos, influir sobre ellos $y$, en caso contrario, tomar una posición ante ellos y defenderlos. La observación de las representaciones sociales podría parecer una tarea fácil (pero es compleja) ya que circulan en los discursos, en las palabras, en los mensajes, en los medios de comunicación, cristalizadas en las conductas y las disposiciones materiales o espaciales (Jodelet, 1989). 
Popularizar la ciencia: consideraciones sobre la "otredad" y sus implicaciones éticas

- Como sistemas de valores, ideas y prácticas, cumplen una doble función: por una parte, establecen un orden que permite a los individuos orientarse y desenvolverse en su mundo material y social, y por otra, permiten la comunicación entre los miembros de la comunidad, proporcionándoles un código común para la interrelación social, un código que les permite nombrar y clasificar sin ambigüedad los diversos aspectos de su mundo y de su historia individual y grupal (Farr y Moscovici, 1984).

Las tres perspectivas anteriores, tanto el trabajo de Freire en el reconocimiento vocabular del otro, como el concepto de prealimentación de Kaplún, donde se hace énfasis en los procesos simbólicos, así como las aportaciones de la teoría de las representaciones sociales, cuyo autor es Serge Moscovici en el estudio de las producciones de imágenes y sentidos, proporcionan una visión dinámica de la percepción de la ciencia en diversos sectores poblacionales. ${ }^{6}$

Es sabido que en el estudio del sentido común del otro, afloran los sentimientos, los pensamientos, las actitudes, las creencias, las imágenes, los estereotipos, los gustos y costumbre sobre un tópico en específico. En este sentido, dar cuenta primero de lo que significa para el "otro" u "otros" la ciencia, significa también avanzar en el terreno para la puesta en práctica de estrategias -en el sentido de acciones transformadoras- popularizadoras con respecto a la ciencia, el científico y la actividad científica, anteponiendo las cuestiones éticas en el sentido más amplio de la integridad humana.

\section{Conclusiones.}

Entender al "otro", a la otredad, significa entrar en sus producciones sociales y simbólicas; significa desentrañar sus construcciones sociales culturales tanto globales como en los niveles medios y de grupo, que sobre la ciencia suceden en el transcurso de la vida diaria de las personas. Desentrañar estas construcciones, estas percepciones, estas representaciones sociales de la ciencia, constituye dar un paso más para concretizar propuestas en pro de una popularización de la misma, basada no en lo que "se cree que se cree del otro", sino basada en evidencias rigurosas, en investigaciones serias que tomen en cuenta las creencias, los sentimientos, las actitudes, los estereotipos, los usos y costumbres, etc., que giran en torno a la ciencia, con la esperanza de buscar acciones más democráticas para todos los involucrados en este quehacer tan necesario e importante, sobre todo para el entendimiento y búsqueda de acciones que permitan una aprehensión de la ciencia con miras a propiciar una mayor comunicación y entendimiento de los logros y avances en los contextos mediatos e inmediatos, con miras a un mayor fortalecimiento como nación.

AGO.USB Medellin-Colombia V. $9 \quad N^{\circ} 1$ PP. 1-294 Enero-Junio 2009 ISSN: 1657-8031 


\section{Referencias Bibliografías}

Arendt, H. (1993). La condición humana. Barcelona: Paidós.

----(1996). La crisis en la educación. Entre el pasado y el futuro. Barcelona: Península.

Bourdieu, P. (2000). Los usos sociales de la ciencia. Buenos Aires: Nueva Visión.

De Certeau, M. (1996). I. Artes de hacer. La invención de lo cotidiano. México: Universidad lberoamericana.

Farr, R. (1993). Theoretical perspective. Common sense, science and social representations. Public Understanding of Science, Vol.2, 189-204.

Sage Publications (www.sagepublications.com)

Farr, R. y Moscovici, S. (1984). Social Representations. Cambridge, U.K: Cambridge University

Freire, P. (1969). La educación como práctica de la libertad. México: Siglo XXI.

(1973). Pedagogía del oprimido. Buenos Aires: Siglo XXI.

--- (1974). ¿Extensión o comunicación? La concientización en el medio rural. México: Siglo XXI.

Foucault, M. (1976). Vigilar y castigar. México: Siglo XXI.

Habermas, J. (1998). La modernidad, un proyecto incompleto. En Foster, H. y otros. La posmodernidad. México: Kairos.

(1992). Teoría de la acción comunicativa, Vol. 2. Buenos Aires: Taurus.

Herzlich, C. (1975). La representación social, en Moscovici, S. (coord.) Introducción a la Psicología Social, España:Planeta. 
Huergo, J.A. (2001). La popularización de la Ciencia y la Tecnología: Interpelaciones desde la comunicación. Red de Popularización de la Ciencia y la Tecnología para A m é r i ca Latina y el Caribe. Seminario Latinoamericano Estrategias para la Formación de Popularizadores en Ciencia y Tecnología. Red-POP-Cono Sur. La Plata, 14 al 17 de mayo.

Jodelet, D. (1989). Representaciones Sociales, Paris: PUF, Paris (traducción de D. Páez y C.San Juan).

Kaplún, M. (1992). Repensar la educación a distancia desde la comunicación. Cuadernos de Diálogos, Cuad. N1/4 23, Lima.

(1996). El comunicador popular. Buenos Aires: Lumen-Humanitas.

Moscovici, S. (1979). El psicoanálisis, su imagen y su público. Buenos Aires: Huemul S.A.

(1988). Notes towards a description of social representations. European Journal of Social Psychology, Vol. 18, 211 1-250.

Moscovici, S. y Marková, I. (2003). La presentación de las representaciones sociales: diálogo con Serge Moscovici. En Castorina, J.A. (comp.) Representaciones Sociales. Problemas teóricos y conocimientos infantiles, Barcelona: Gedisa.

Sánchez de Aparicio y B., G.A. (2007). La persona del investigador como dispositivo metodológico de la investigación. Algunas reflexiones. Documento inédito, para uso académico restringido.

Sánchez-Ruiz, E. E. (2004). Comunicación y Democracia. México:IFE-Cuadernos de Divulgación de la Cultura Democrática.

"El términos "otro" u "otros" no se maneja en este escrito de manera irrespetuosa, sino que se utiliza de esta forma para diferenciarlo del "yo" o del "nosotros" en el discurso; de esta manera se hace referencia a la "otredad" para dar cuenta de los diferentes usos que se le ha dado a esa otra parte de la cual todos somos una unidad, aún en la diversidad, a lo largo del acontecer histórico. 
${ }^{2}$ Huergo (2001) ha trabajado extensamente acerca de la popularización (término que no debe entenderse como divulgación) de la ciencia, cuyos conceptos-sintetizados en los siguientes párrafos- reflejan gran parte de su trabajo.

${ }^{3}$ Investigación que se presenta como tesis doctoral, publicada por vez primera vez en 1961 y en la que da a conocer a la teoría de las representaciones sociales.

${ }^{4}$ Existen en la actualidad diversos países donde periódicamente se estudian las opiniones, las imágenes, las percepciones, etc., de la ciencia en diferentes sectores y grupos sociales. Estados Unidos de América inició este "movimiento" en 1950, y desde entonces cada dos años realiza una encuesta a nivel nacional, preocupación seguida por una ya larga lista de países (México incluido) que llevan a cabo estudios de este tipo a ese nivel, y cuyas consecuencias han dado la oportunidad de intercambiar información, establecer redes y tomar acuerdos sobre la importancia de la divulgación y popularización de la ciencia.

${ }^{5} \mathrm{Se}$ presenta una lista de conceptos considerados como iniciales y básicos, bajo el entendimiento de que la teoría de las representaciones sociales no se reduce a estos.

${ }^{6}$ Actualmente la autora de este escrito está llevando a cabo una investigación doctoral con el propósito de conocer las representaciones sociales de la ciencia en alumnos de pregrado del CUCS, Universidad de Guadalajara. La información que se ha intercambiado con los estudiantes es por demás interesante (se adelanta sólo un poco de un vasto análisis): abundan entre ellos esteotipos muy remarcados que han coincidido con otros estudios en diferentes parajes del mundo: el científico es un hombre (no mujer) con muchos conocimientos, casi sabio, pero apartado de la sociedad, raro y con apariencia desaliñada. La ciencia es, por lo tanto, para unos cuantos (no cualquiera puede acceder a ella). Estas representaciones sociales, productos del contacto con diferentes fuentes de formación e información, inhiben a los jóvenes estudiantes a acercarse a actividades de tipo científicas, alejando así a potenciales investigadores. 